\title{
Protecting the right to health of internally displaced mothers and children: the imperative of inter-cluster coordination for translating best practices into effective participatory action
}

K.M. Bile, ${ }^{1}$ A. Hafeez, ${ }^{2}$ G.N. Kazi ${ }^{3}$ and D. Southall ${ }^{4}$

$$
\begin{aligned}
& \text { حماية الحق في الصحة للأمهات والأطفال النازحين داخلياً: حتمية التنسيق بين المجموعات لترجمة أفضل الملارسات إلى أعهال } \\
& \text { تشار كية فعالة } \\
& \text { خليف بله محمود، سدأ حفيظ، غلام نبي قاضي، ديفيد ساوث هول }
\end{aligned}
$$

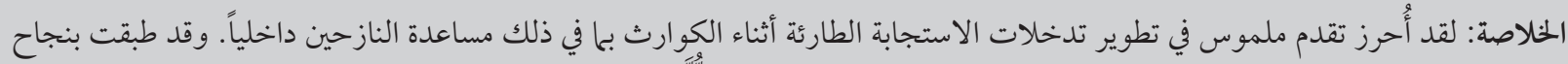

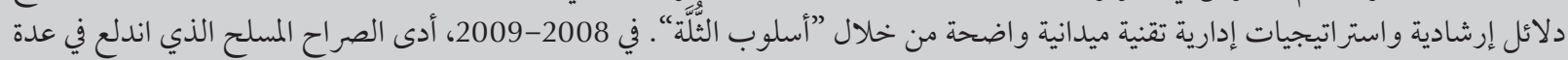

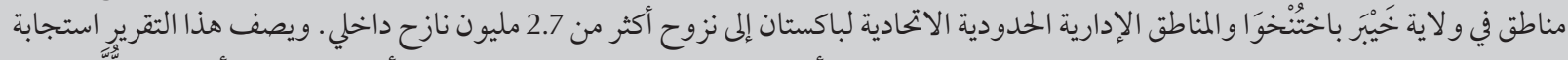

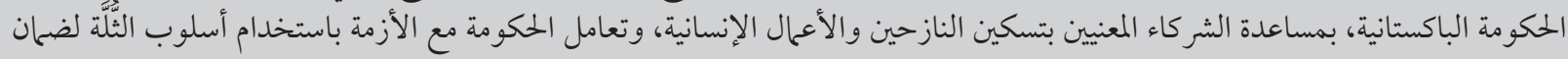

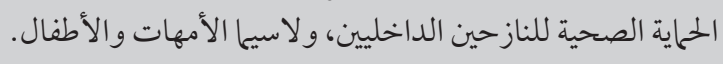

ABSTRACT Substantive progress has been achieved in advancing emergency response interventions during disasters including assistance of internally displaced persons (IDPs). Explicit operational technical guidelines and management strategies have been successfully applied through the "cluster approach". In 2008-09 armed conflict in several districts of the Khyber Pakhtunkhwa (KP) province and the Federally Administered Tribal Areas (FATA) of Pakistan resulted in over 2.7 million IDPs. This report describes the response by the Pakistan government, assisted by the hosting populations and humanitarian partners, to deal with the crisis using the cluster approach to ensure the health protection of the IDPs, particularly mothers and children.

Protéger le droit à la santé des mères et des enfants déplacés à l'intérieur de leur propre pays : une coordination intergroupes est impérative pour traduire les meilleures pratiques en action participative efficace

RÉSUMÉ Des progrès conséquents ont été accomplis en matière d'interventions d'urgence au cours de catastrophes, y compris pour assister les personnes déplacées à l'intérieur de leur propre pays. Des directives techniques opérationnelles claires et des stratégies de gestion ont été appliquées efficacement au moyen de l'approche modulaire. En 2008 et 2009, plusieurs districts de la province de Khyber Pakhtunkhwa et des zones tribales sous administration fédérale du Pakistan ont été le lieu d'un conflit armé qui a entraîné le déplacement de plus de 2,7 millions de personnes. Ce rapport décrit la riposte du gouvernement pakistanais, aidé par les populations hôtes et par des partenaires de l'aide humanitaire pour faire face à la crise en ayant recours à l'approche modulaire pour protéger la santé des personnes déplacées à l'intérieur de leur propre pays, en particulier les mères et les enfants. 


\section{Introduction}

Natural and man-made disasters have become frequent in recent times, with global estimates of the internally displaced persons (IDPs) caused by conflicts from 1990 to 2009 exceeding 23 million. Around 46\% have occurred in the Eastern Mediterranean Region (EMR) of the World Health Organization (WHO) [1,2]. The tragic scenarios to which IDPs were exposed has necessitated the protection of their human rights, including the rights to health of mothers and children, violations of which have become a feature of most of these crises [2-4].

Furthermore, the protection of health-care systems in times of conflict has remained a critical factor influencing health care available to the affected population [5-7]. The First Geneva Convention was signed in 1863 , which addressed the care for sick and wounded soldiers during wartime and recognized the neutrality of medical personnel, hospitals and ambulances identified by the emblem of the Red Cross [4]. The Second and Third Geneva Conventions were adopted in 1906 and 1929, and addressed care for the wounded, sick and shipwrecked armed forces and the rights of prisoners of war respectively. The protection of civilians and medical services in time of war was endorsed in 1949 by the Fourth Geneva Convention that forbids the use of hospitals for nonhumanitarian duties, while mandating the provision of necessary relief to affected civilian populations [8]. The 1949 Convention was reinforced in 1977 by 2 additional protocols relating to the protection of victims of international and non-international armed conflicts respectively, providing a legal avenue for the internationally recognized protection of the rights of IDPs $[9,10]$.

The limited disaster response capacity of most affected nations has necessitated the engagement of the international humanitarian community $[5,11,12]$. To effectively address these global challenges, an Inter-Agency Standing Committee (IASC) was established in 2005 that soon conceived the launching of the cluster approach for 9 priority sectors that included health, nutrition, water and sanitation, protection and emergency shelter. The IASC identified cluster lead organizations for each, while the food security cluster was deliberated in $2010[12,13]$. These deliberations led to a Preliminary Guidance Note put into effect in 2006 by the IASC whereby the cluster approach has since been globally recognized as the best mechanism for coordinating and implementing effective and cohesive relief and rehabilitation during humanitarian response operations [8].

Pakistan adopted the cluster approach during the massive 2005 earthquake, and learned many lessons concerning the participatory management of humanitarian relief operations, the legitimate demand for results and accountability, and the protection of the human rights of IDPs [14]. Subsequently, Pakistan was affected by the cyclone and floods of 2006 in Sindh and Balochistan provinces and by the 2007 earthquake that hit Balochistan. These 3 disasters cumulatively affected over 8 million people, of which close to $50 \%$ became IDPs at some point in time. Almost all returned voluntarily to their places of residence through a well-managed governmentled humanitarian response, rehabilitation and reconstruction effort. During these adversities a cadre of emergency response managers and professionals was groomed and institutional capacities created by establishing the National Disaster Management Authority to coordinate emergency preparedness and response interventions in the country. In 2008-09 armed conflict in several districts of the Khyber Pakhtunkhwa (KP) province and the Federally Administered Tribal Areas (FATA) of Pakistan resulted in over 2.7 million IDPs [15] and the capacities and assets of the National Disaster Management Authority were skilfully utilized to assist them.
The health-related human rights of Pakistan's IDPs of 2008-09 were closely reviewed. Relevant deliberations on health care in conflict were raised in a conference organized in London in November 2010 by the International Child Health Group, Royal College of Paediatrics and Child Health and Maternal and Child Health Advocacy International, with extended experience in Pakistan. The conference resulted in a resolution on the need to ensure the protection of health care during armed conflict [16]. The pervasive lack of protection for health care during armed conflicts outlined by the conference has consolidated the focus of this report.

This report shares the lessons learned from the Pakistan IDPs crisis of 2008-09 and describes how the vulnerable groups, especially mothers and children, were ensured the required essential health services as an inalienable human right. It substantiates the criticality of health protection among displaced mothers and children and the obligation to enhance their resilience and survival through a safeguarded and strengthened health system network.

\section{Overview of the interventions successfully used to assist IDPs in Pakistan}

The Health Cluster (HC) led by the government health authorities and WHO mobilized the participation of 46 humanitarian partners to assist the IDPs, of which over $60 \%$ were mothers and children. A package of vital primary health care (PHC) activities and life-saving emergency referral support interventions was provided. These interventions included the protection of maternal, neonatal and child health care rights implemented by a network of first-level care facilities, mobile and camp-based health services and 11 district hospitals. The 
following outline illustrates the key interventions executed that had a positive impact on the protection of these vulnerable IDPs.

\section{Organizing the humanitarian response}

HC partners conducted regular meetings at national, provincial and district levels to promptly address the planning, implementation and monitoring of essential health response interventions. There was a coordinated resource mobilization, and the provision and management of essential medicines, supplies, equipment and operational logistics. Universal health coverage was facilitated by the official registration of all IDPs at multiple hubs created by the National Disaster Management Authority, and technically supported by both the National $\mathrm{Da}$ tabase and Registration Authority and the United Nations Refugee Agency (UNHCR). All households, including those headed by women, were provided with identity cards to access the humanitarian relief assistance. Figure 1 shows the required multisectoral approach for protecting the health rights of IDPs and mothers and children in particular.

Box 1 illustrates the scope of critical services provided together with the protection required for the health system to perform adequately and provide essential and life-saving health services to IDPs. These relief interventions were planned and implemented in all IDP hosting districts, coordinated by the National Disaster Management Authority, the provincial government relief commission and the Provincial Disaster Management Authority supported by several federal departments, including health. These efforts were extensively complemented by HC humanitarian relief organizations co-led by the government and WHO. Protection was also provided by hosting communities who sheltered and assisted $88 \%$ of the IDPs, each family accommodating on an average 1.2 displaced families. To mobilize this response effectively, HC partners developed a joint health response strategy, complemented by a set of standard operational guidelines that were collectively pursued (Box 2). The guidelines predominantly addressed the health needs of mothers and children and contributed significantly to the care of these vulnerable groups.

\section{Emerging disparities in access to care}

Humanitarian response partners in Pakistan discerned a difference in accessing essential health-care services by IDPs living in camps relative to those hosted by local communities; the former having better access to health services. Conversely, IDPs hosted by families were perceived to live in more socially conducive and protective settings. Table 1 illustrates a qualitatively assessed range of determinants and their potential influence on this observed difference. To bridge these disparities, HC partners strengthened the service delivery capacity of the PHC facilities and hospitals with focus on maternal, neonatal and child health care $(\mathrm{MNCH})$, including reproductive health, and raised the scope of service utilization for the out-of-camp IDPs and hosting populations. Likewise, the in-camp safety and protection measures were enhanced.

\section{Health system strengthening}

The rapid health needs assessment carried out at the outset of the crisis identified performance gaps in the health response strategy led by a scarcity of female health workers, and a paucity of medicines, relevant supplies and equipment. Over a third of the PHC facilities could not provide basic emergency obstetric and neonatal care and a similar proportion of the 11 district hospitals operating in the IDPs' catchment areas was unable to deliver comprehensive emergency obstetric and neonatal care services thus, necessitating urgent health system strengthening.

\section{Basic necessities \\ Food, water, shelter, clothing, \\ health \& sanitation} housing and livelihoods \& work

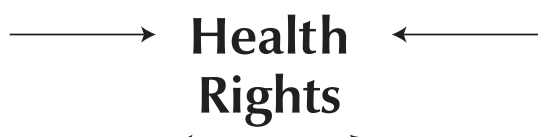

IV. Protection of special groups of persons

Mothers, children and adolescents, old persons, people living with HIV/AIDS, single parenthouseholds, ethnic and religious minorities \& indigenous populatioons

V. Civil and political rights

Documentation, free movement, free life $\&$ missing dead relatives 


\section{Critical service operations}

1. Organizing the Health Cluster to coordinate all health relief operations

2. Assessing health protection needs of IDPs and their hosting population

3. Ensuring the access of IDPs to health relief operations and to all necessary health care facilities

4. Ensuring the availability of skilled health workers and sustained access to the female health workforce

5. Organizing essential care services with focus on $\mathrm{MNCH}$ including reproductive health and family planning

6. Promoting breast feeding \& nutrition supplementation

7. Treating STIs

8. Preventing disease outbreaks

9. Providing immunization services

10. Offering specialized referral care

11. Facilitating access to psychosocial support \& mental health services

12. Protecting single parents with children

13. Sustaining stocks of medical supplies and drugs, including oxygen

14. Caring for persons with disability and provision of supportive aid

15. Ensuring outreach health services to those unable to reach facilities

16. Organizing reconstruction and upgrading of health facilities

17. Setting minimum operating standards for health response

18. Recording and reporting all violations with a negative impact on the functioning of health services

19. Organizing community-based care and encouraging IDPs' active participation

20. Undertaking health education and promotion interventions

\section{Protection required for the health systems}

1. Protecting PHC and health facilities, hospitals and clinics operating in the disaster zone, including military health facilities, including physical protection and security measures for hospitals and checkpoints as necessary

2. Ensuring fast track transfer of essential drugs and medical supplies

3. Protecting health workers and health volunteers from attack and intimidation during their work, in their homes and to and from their places of work.

4. Ensuring safe transport of sick and injured patients to and from health facilities and preventing attacks on the sick and wounded.

5. Ensuring the safety of UN relief teams and other humanitarian organizations including registered national and international NGOs active in emergency health response operations

6. Banning the storage of weapons in hospitals, launching attacks from health-care facilities or carrying of members of armed forces in ambulances or any other health logistics except when transporting the seriously injured

7. Protecting and supporting national and international parties assisting the health system with provision of supplies, equipment and vital consumables that are essential to execute life-saving surgical, anaesthetic and other vital services

8. Ensuring the provision of safe corridors to care seekers to access health facilities

9. Documenting violations to the functioning of health services in conflict zones

10. Establishing formal and informal contact focal points with relevant authorities for enhancing protection and for acting on reported violations

11. Upholding the neutrality and impartiality of the health care system and the legitimacy of health workers assisting the sick and injured irrespective of the conflict zone they serve in and promoting preventive policies, while not coercing health workers to make statements that could compromise their neutral stance

12. Preserving all essential amenities of the health system with special attention to electricity and water supply

13. Training the health workforce in undertaking essential preventive security measures and in handling situations related to intimidation, kidnapping and violence

$I D P S=$ internally displaced persons; $M N C H=$ maternal, neonatal and child health; $S T I s=$ sexually transmitted infections; UN=United Nations; NGOs = nongovernmental organizations

The provincial health department mobilized female physicians from teaching hospitals in the provincial capital Peshawar, who commuted daily to the camps and health facilities of the IDP hosting districts. The support offered by professionals proficient in Pashto, the IDPs' spoken language, led to a substantial enhancement of health services use with visible improvement in $\mathrm{MNCH}$ outcomes. Implementation of the operational standards and guidelines established by $\mathrm{HC}$, which specified the quantity and quality of services to be provided at each level of care, were made mandatory for all national and international health partners assisting the IDPs. Moreover, the procurement and operational management of essential medicines were coordinated by WHO in liaison with the government and $\mathrm{HC}$ partners. Other essential supplies and equipment were also provided to ensure the effective functioning of these facilities. The availability of running water and electricity was ensured at all times by providing generators to hospitals and facilitating water supply connections to secure the provision of emergency services.

\section{Health education and promotion}

During the course of this crisis, Lady Health Workers, a national cadre of trained female community health workers providing PHC services to 
Box 2 The Health Cluster (HC) strategy for the internally displaced persons (IDPs) focusing on the protection of the right to health of mothers and children and the services for which standard operating guidelines were set for implementation

\section{Pakistan HC strategy for the IDPs}

- Coordination of health action

- Initial rapid assessment

- Disease surveillance

- Control of disease outbreaks

- Standard essential service package

- Mass vaccination

- MNCH focused action with IMNCI implementation

- Nutrition care and surveillance

- Health promotion and education

- Essential medical supplies

- Safe drinking-water

- Mental health \& psychosocial support

- Assistance of persons with disabilities

\section{Services for which standard operating guidelines were set}

- Treatment of common ailments

- Integrated $\mathrm{MNCH}$, reproductive health including family planning

- Expanded Programme on Immunization

- Nutrition

- Malaria case management

- Tuberculosis treatment through DOTS

- Minor surgical procedures and emergency health

- Mental health and psychosocial support

- Care for persons with disability

- Community-based health promotion and education

- Laboratory and X-ray facilities

- Essential drugs management and their rational use

- Disease Early Warning System (DEWS) for epidemic control

- Inpatient facility: only in RHCs and hospitals

- Ambulance services

$M N C H=$ maternal, neonatal and child health; IMNCI = integrated management of neonatal and childhood illnesses; $R H C S=$ rural health centres.

rural and peri-urban communities, were mobilized. Those operating in the IDPs' hosting districts paid daily visits to the camps and first-level care facilities and promoted health education activities. They organized focus group sessions for in-camp mothers and encouraged them to attend these sessions using an incentive-based approach called the "Bangle Project". Colourful traditional bangles were provided to mothers successfully completing these health education and promotion sessions. The programme was conceived by WHO and implemented jointly with the national health authority and several nongovernmental organizations (NGOs). To enhance health knowledge, attitude and practice, the training contained a package of health education and promotion messages covering: the prevention, control and management of acute diarrhoea; the feeding of infants, especially breastfeeding, weaning foods and supplementary feeding; reproductive health services; immunization; and promotion of personal hygiene, including hand-washing, a clean environment, food safety and water and sanitation protection measures. Prior to its commencement, a baseline assessment revealed that less than $5 \%$ of the internally displaced mothers had adequate knowledge about these vital health issues. The training material designed was first pretested to ensure that the messages were technically sound, culturally relevant and easily understood in relation to the desired outcomes.

\section{Averting excess morbidity and mortality}

To mitigate the risk of infectious disease outbreaks, the Disease Early Warning System (DEWS) surveillance network was established, ensuring the active participation of at least $85 \%$ of the facilities in the catchment area of IDPs. DEWS covered the daily case reporting of 16 prioritized diseases and conditions that included acute lower and upper respiratory infections, acute diarrheal diseases/ bloody diarrhoea, haemorrhagic fever, acute jaundice syndrome, malaria, measles, meningococcal meningitis, acute flaccid paralysis, neonatal tetanus, scabies and unexplained fever. Notified cases were investigated and a response mobilized when the occurrence of an outbreak was imminent or verified. Mass vaccination for measles was carried out at the outset of the crisis and covered children between 6 months and 13 years of age, both from displaced and hosting populations; it was complemented by routine immunization.

The number of outbreaks reported during the first year of the IDP crisis was compared with the numbers reported from the 2005 earthquake during the same interval. The 2 disasters' recorded diarrhoeal outbreaks accounted for $53.5 \%(54 / 101)$ of reported outbreaks, predominantly characterized as cholera, while vaccine preventable disease (VPD) outbreaks, predominantly of measles, contributed to $22.8 \%(23 / 101)$ 


\begin{tabular}{|c|c|c|}
\hline Access to health care services and other facilities & In-camp IDPs & IDPs hosted by families \\
\hline \multicolumn{3}{|l|}{ Access to health care services } \\
\hline Vaccinations & ++++ & ++ \\
\hline Management of common illnesses & ++++ & ++ \\
\hline Management of malnutrition & ++++ & +++ \\
\hline Vector control & ++++ & + \\
\hline Reproductive health plus family planning services & +++ & ++ \\
\hline Care for severely malnourished children & ++++ & +++ \\
\hline Support to persons with disability & ++++ & ++ \\
\hline Psychosocial support & ++++ & ++ \\
\hline Prescribed medication & ++++ & +++ \\
\hline Ambulance services & ++++ & ++ \\
\hline Emergency hospital services & ++++ & +++ \\
\hline Referral services & ++++ & ++ \\
\hline \multicolumn{3}{|l|}{ Access to other facilities } \\
\hline Safe drinking-water in comfort & ++++ & ++ \\
\hline Sanitary facilities of hygienic standard and comfort & +++ & ++ \\
\hline Food and feeding centres & ++++ & +++ \\
\hline Nutrition education through growth monitoring & ++++ & ++ \\
\hline Affording more privacy when breastfeeding & ++ & ++++ \\
\hline
\end{tabular}

$+=$ poor,$++=$ satisfactory,$+++=$ good,$++++=$ excellent .

of the outbreaks, cumulatively accounting for $76.2 \%$ of the total number of all reported outbreaks indicating the need for active surveillance. The proportion of diarrhoea outbreaks recorded among IDPs during the conflict $[73.8 \%$ $(31 / 42)]$ was significantly higher than that reported during the earthquake [39\% (23/59)] (OR $=4.4,95 \% \mathrm{CI}$ : 1.7-11.5). However, the proportion of VPD outbreaks among IDPs during the conflict $[2 \%(1 / 42)]$ was significantly lower than VPD outbreaks during the earthquake [45\% (22/59)] $(\mathrm{OR}=24.4,95 \%$ CI: 3.2-509.3). Similarly, no hepatitis A and E outbreaks were reported among IDPs during the conflict crisis, while during the earthquake disaster, $18.6 \%(11 / 59)$ of outbreaks were due to hepatitis A and $\mathrm{E}$.

\section{Safeguarding mothers' and children's rights to adequate nutrition}

A nutrition assessment carried out in May 2009 among the IDPs in camps and in host communities revealed that the prevalence of acute malnutrition among the children under 5 years was less than $4 \%$. The assessment was followed by an extensive health promotion and education intervention. Nutrition surveillance was also introduced by WHO to ensure that nutritional problems were promptly detected and necessary responses applied, including nutrition rehabilitation therapy for the severely malnourished. To maximize the impact of this initiative, interventions of community-based management of acute malnutrition were advanced by the nutrition cluster in partnership with the health, water and sanitation and the hygiene clusters.

\section{Water and sanitation}

To provide safe water to the IDPs, deep bore wells were the most used sources. All accessible hand pumps were tested and those found polluted were immediately closed. Water transported by tankers to the camps was chlorinated, whether assigned for drinking or for other uses, and compliance closely monitored by a team of qualified professionals assigned to this task. Similarly, separate male and female sanitary facilities with screened fences were constructed in the camp to preserve privacy and encourage use. The sanitary latrines had hand-washing sinks attached with soap. Sanitary workers were assigned to maintain the hygiene of the latrines.

\section{Role of emergency shelter and protection clusters}

The government assisted by the humanitarian partners ensured the safe evacuation and registration of all IDPs and their immediate and free access to emergency response interventions. The emergency shelter cluster selected campsites for the IDPs and ensured that those originating from the same geographical areas were helped to reside in adjacent camp spaces as an effort to promote social and ethnic cohesion. Key social services were ensured with the 
provision of cooking utensils and other essential non-food items, including the open access of women and children to food distribution centres. The protection cluster ensured the registration of about 1100 separated and unaccompanied children as well as about 3500 families headed by children or women. A team was established to register and refer all observed violations, particularly against children, to the established child protection committees. The work of these committees facilitated the protection of these vulnerable groups against any potential abuse, violence or exploitation.

\section{Discussion}

Protecting the rights to health of internally displaced mothers and children has been placed at the centre of major humanitarian disasters and recognized as a key determinant of the success of relief and recovery operations [10-12]. In Pakistan, a partnership was forged between the civilian government, the Pakistan Army and the humanitarian community led by the United Nations, collectively pursuing the cluster approach and its operational principles as the core strategy for emergency preparedness and response [16-18]. To harmonize emergency response operations, the HC has formulated a common health response strategy for IDPs along with a set of standard technical guidelines focusing on the protection of maternal, neonatal and child health rights [10]. The "Delivering as One" initiative launched a few years earlier in Pakistan has contributed to this harmonized accomplishment [19]. Although the HC took on the flagship role in protecting the health rights of displaced mothers and children, the effectiveness of this endeavour was inextricably linked with the broader protection framework generated through the fundamental pillars of the globally recognized human rights, the safeguarding of which has been mandated during disasters [11]. This framework includes the protection of life, security, physical, mental and moral integrity, and mitigation of the negative impact of natural hazards, landmines and violence, particularly in relation to gender; the protection of basic necessities such as food, water, shelter, clothing, health and sanitation and livelihood; and the protection of specific groups of persons including mothers, neonates and children, adolescents, aged persons, people living with HIV/AIDS and single-parent households $[11,14]$. This wider imperative of a rights approach to mothers and children has enhanced the understanding of $\mathrm{HC}$ partners concerning the necessity of inter-cluster collaboration and alliance building.

Damage resulting from armed conflict often disrupts infrastructure and impedes the operational viability of primary and secondary health-care services, many being destroyed or rendered unsafe by frequent assault, in violation of internationally agreed conventions $[9,10]$. In Pakistan, these actions inflicted severe damage and disruption to a health system already under-funded and functioning at sub-optimal level, thus posing serious challenges to the health care needs of the IDPs. This prompted a health system strengthening approach operating surge capacity in all facilities, especially hospitals with core health response interventions being guided by the rapid assessment findings [5,7,20-23]. The National Health Emergency and Response Network established in the federal Ministry of Health has contributed to this endeavour. An immediate undertaking was the redistribution of existing human resources for greater efficiency and the deputation of additional health workers to address the shortage of skilled professionals, especially nurses, midwives and female medical doctors. Efforts were also made to ensure the provision of emergency medicines and essential supplies and equipment for the regular implementation of $\mathrm{MNCH}$ and other critical health services. The health system strengthening focused on a package of essential health services, support to laboratories, blood banks, operating theatres, anaesthesia and life-support equipment, $\mathrm{MNCH}$ emergency care units, and the provision of ambulances and rectified the issue of accessing emergency response interventions by both in-camp and out-of-camp IDPs.

Unfortunately, health system strengthening efforts are often constrained by the inadequate share from the humanitarian appeal allocated to $\mathrm{HC}$ and the overall delayed government and donor response. The successful implementation of the emergency health response was found to be more attainable when the HC share of appeal funds was $\geq 10 \%$, of which $30 \%$ was assigned to health system strengthening for scaling up $\mathrm{MNCH}$ and other life-saving interventions, 25\%-30\% used for the procurement of essential pharmaceutical and medical supplies and $<30 \%$ allotted for the recruitment of international health expertise. These operational findings should encourage systems research in order to generate evidence for future emergency health response interventions aimed at mitigating the impact of natural and manmade disasters.

Building health knowledge, attitude and practice capacities among displaced mothers was another major contributor to the protection of the right to health of mothers and children. Mothers were successfully encouraged to realize their role in disease prevention by inculcating healthier attitudes and behaviours related to hand-washing, environmental hygiene, antenatal care, child feeding, the use of oral rehydration therapy and immunization. The bangle initiative emerged as a socially valued incentive, as colourful bangles in Pakistan's cultural context signify happiness and hope. The implementation of this health promotion initiative by culturally sensitive female health workers generated wider 
acceptance among displaced mothers and approval from their male family members. The initiative created a visible interest among mothers and imparted maternal and child home health care skills, corroborating the relevance and cost-effectiveness of this participatory scheme. The skills attained were relevant both during displacement and upon the IDPs' return to their original homes during the recovery phase.

The DEWS initiative acted as a barrier against epidemics by offering the capacity to interrupt or mitigate the spread of disease $[24,25]$. During the course of this crisis, the significant reduction in measles outbreaks observed, relative to previous disasters, was attributed to the timely mass vaccination of children covering both IDPs and their hosting communities that were backed up by sustained routine immunization. The significantly higher number of diarrhoeal outbreaks among IDPs during the conflict relative to those recorded during the earthquake could be partly explained by the overwhelming floods that swept this region during the monsoons of 2008 and 2009. However, most of these outbreaks were limited in scope because of universal water chlorination, improved sanitation and the timely application of disease control measures. Conversely, the outbreaks due to hepatitis A and $\mathrm{E}$ viral infections during the earthquake, relative to the IDPs' hosting districts, may be attributed to the contamination of the surface water used after the earthquake, their lower access to sanitation and possible higher susceptibility to these viral infections, being displaced from isolated mountainous areas.

The interface between the nutrition and health clusters was operationally complementary, whereby the nutrition assessment survey and surveillance guided the provision of fortified complementary foods, vitamin A supplements, care for the severely malnourished and promotion of breastfeeding. The impact of these interventions was further strengthened by MNCH-related emergency response interventions, highlighting the value of close intercluster coordination.

Universal water chlorination and regular monitoring was mandated and jointly supported by the water, sanitation and hygiene (WASH) and health clusters. This helped avert the problem faced during the 2005 earthquake response where a major cholera outbreak occurred because of the preferential consumption of unchlorinated water, designated for other uses, instead of the chlorinated water supplied for drinking because of the perceived unpleasant smell and taste. Likewise, the low use of sanitary facilities during the 2005 earthquake was avoided by the construction of culturally and hygienically acceptable latrines.

The effective response to the protection of the rights to health of mothers and children during emergencies depends on many factors: the hazards that IDPs face, their inherent vulnerabilities, the magnitude of the response, the protection and support offered to health facilities and their workforce, and the effectiveness of the $\mathrm{HC}$ and inter-cluster operations management co-led by host governments and their humanitarian partners $[6,8]$. In Pakistan, the proactive and successful support provided to IDPs during their early evacuation and extended displacement period, the safe and assisted voluntary repatriation, and the comprehensive recovery plan had a major positive influence on providing this protection. These interventions were made possible through an endorsed human rights framework, timely mobilized health systems strengthening and life-saving technical interventions, adequate deployment of health workforce and the pursuit of upstream policy and strategic operational plans implemented in unison by the government and humanitarian partners.

\section{References}

1. International Displacement Monitoring Center. Global Statistics. IDP estimates (2001-2009) (http//www. IDMC/ global statistics: IDP country figures.mht, accessed, accessed 23 October 2011)

2. Leus X, Wallace J, Loretti A. Internally displaced persons. Prehospital and Disaster Medicine, 2001, 6:116-123.

3. Mkoji GM. Civil turmoil in Africa: a potential setback in the fight against diseases. African Journal of Health Sciences, 1996, 3:109.

4. Sapir DG. Natural and man-made disasters: the vulnerability of women-headed households and children without families. World Health Statistics Quarterly, 1993, 46:227-233.

5. Paturas JL et al. Collective response to public health emergencies and large-scale disasters: putting hospitals at the core of community resilience. Journal of Business Continuity \& Emergency Planning, 2010, 4:286-295.
6. Leonard SR, Bittle DM. Responsibility for protection of medical workers and facilities in armed conflict. Lancet, 2010, 375:329-340.

7. Gausche-Hill M. Pediatric disaster preparedness: are we really prepared? Journal of Trauma, 2009, 67(S2):73-76.

8. IRC. International Humanitarian Law - Treaties \& Documents. Convention (IV) relative to the Protection of Civilian Persons in Time of War. Geneva, 12 August 1949 (http://www.icrc.org/ihl. nsf/385ec082b509e76c41256739003e636d/6756482d8614 6898c125641e004aa3c5, accessed 23 October 2011).

9. IRC. International Humanitarian Law - Treaties \& Documents. Protocol additional to the Geneva conventions of 12 August 1949, and relating to the protection of victims of international armed conflicts (Protocol I), 8 June 1977 (http://www.icrc.org/ihl.nsf/ FULL/470?, accessed 23 October 2011).

10. IRC. International Humanitarian Law - Treaties \& Documents. Protocol additional to the Geneva conventions of 12 August 1949, and relating to the protection of victims of non- 
international armed conflicts (Protocol II), 8 June 1977 (http:// www.icrc.org/ihl.nsf/7c4d08d9b287a42141256739003e63 6b/d67c3971bcfflc10c125641e0052b545, accessed, 23 October 2011).

11. Human rights and natural disasters: Operational guidelines and field manual on human rights protection in situations of natural disaster. Washington DC, Brookings-Bern Project on Internal Displacement, 2008. (http://www.brookings.edu/ /media/ Files/rc/reports/2008/spring_natural_disasters/spring_natural_disasters.pdf, accessed, 23 October 2011).

12. Interagency Standing Committee (IASC). Guidance note on using the cluster approach to strengthen humanitarian response, 24 November 2006 (http://www.humanitarianreform.org/humanitarianreform/Portals/1/Resources\%20\&\%20tools/IASCGUIDANCENOTECLUSTERAPPROACH.pdf, accessed, 23 October 2011).

13. Partnership to Cut Hunger and Poverty in Africa. November 2010 update on the proposed food security Cluster, 2010 (http:// www.partnership-africa.org/content/november-2010-updateproposed-food-security-cluster, accessed, 23 October 2011).

14. Inter-Agency Standing Committee. Protecting persons affected by natural disasters: IASC Operational guidelines on human rights and natural disasters. Washington DC, Brookings-Bern Project on Internal Displacement, 2006.

15. Bile KM et al. Learning through crisis: development and implementation of a health cluster strategy for internally displaced persons. Eastern Mediterranean Health Journal, 2010 16(Suppl.):82-90.

16. International Health Protection Initiative. Resolution (http:// ihpi.org/the-resolution, accessed, 19 October 2011).

17. Rahim $\mathrm{M}$ et al. The impact of the disease early warning system in responding to natural disasters and conflict crises in Pakistan. Eastern Mediterranean Health Journal, 2010, 16(Suppl.):114-121.
18. Bukhari SKS et al. Essential medicines management during emergencies in Pakistan. Eastern Mediterranean Health Journal, 2010, 16(Suppl.):106-113.

19. Bile KM, Lashari KA, Shadoul FA. "Delivering as One" UN Reform process improving health partnerships and coordination: Old challenges and encouraging lessons from Pakistan. Eastern Mediterranean Health Journal, 2010, 16(Suppl.):122-131.

20. Fjaer RB. Primary health care in war and disaster and the NorAid system. Prehospital and Disaster Medicine, 1997, 12:183-188.

21. Bradt DA, Drummond CM. Rapid epidemiological assessment of health status in displaced populations-an evolution toward standardized minimum, essential data sets. Prehospital and Disaster Medicine, 2002, 17:178-185.

22. Hafeez A et al. Emergency maternal and child health training courses and advocacy to achieve millennium development goals in a poorly resourced country; challenges and opportunities. Journal of the Pakistan Medical Association, 2009, 59:243-246.

23. Hafeez A et al. Achieving health Millennium Development Goals through capacity building of health workers-ESSEMCH Strategy. Pakistan Pediatric Journal, 2006, 30(1):3-9.

24. Peterson EA et al. The effect of soap distribution on diarrhea: Nyamithuthu refugee camp. International Journal of Epidemiology, 1998, 27:520-524.

25. Centers for Disease Control and Prevention (CDC). Rapid establishment of an internally displaced persons disease surveillance system after an earthquake - Haiti, 2010. MMWR. Morbidity and Mortality Weekly Report, 2010, 59:939-945.

\section{The Humanitarian Emergency Settings Perceived Needs Scale (HESPER)}

The Humanitarian Emergency Settings Perceived Needs Scale (HESPER) aims to provide a quick, scientifically robust way of assessing the perceived serious needs of people affected by large-scale humanitarian emergencies, such as war, conflict or major natural disaster. Perceived needs are needs which are felt or expressed by people themselves and are problem areas with which they would like help.

The HESPER Scale assesses a wide range of social, psychological and physical problem areas. However, it does not provide an answer as to whether, or how to, offer help. It simply aims to identify those serious problems that are common in a population. These problems should then be assessed and addressed in more detail.

The HESPER Scale was developed by the World Health Organization and King's College London in order to fill several gaps in the humanitarian field. It enables needs assessments to be based directly on the views of people affected by humanitarian emergencies, and provides a more accurate picture of the serious problems with which the overall emergency-affected population wants help.

This manual includes the HESPER Scale, as well as a detailed explanation of how to use the HESPER Scale, and how to organise, analyze and report on a HESPER survey.

Further information about this and other WHO publications is available at: http://www.who.int/publications/en/ 